\title{
Analysis of Electric and Hybrid Vehicle Usage in Proximity to Charging Infrastructure in Indiana
}

\author{
Jairaj Desai, Jijo K. Mathew, Howell Li, Darcy M. Bullock \\ Purdue University, West Lafayette, USA \\ Email: desaij@purdue.edu,kjijo@purdue.edu, howell-li@purdue.edu,darcy@purdue.edu
}

How to cite this paper: Desai, J., Mathew, J.K., Li, H. and Bullock, D.M. (2021) Analysis of Electric and Hybrid Vehicle Usage in Proximity to Charging Infrastructure in Indiana. Journal of Transportation Technologies, 11, 577-596.

https://doi.org/10.4236/jtts.2021.114036

Received: August 7, 2021

Accepted: September 4, 2021

Published: September 7, 2021

Copyright $\odot 2021$ by author(s) and Scientific Research Publishing Inc. This work is licensed under the Creative Commons Attribution International License (CC BY 4.0).

http://creativecommons.org/licenses/by/4.0/

\begin{abstract}
This paper explores the movement of connected vehicles in Indiana for vehicles classified by the NHTSA Product Information Catalog Vehicle listing as being either electric (EV) or hybrid electric (HV). Analysis of trajectories from July 12-18, 2021 for the state of Indiana observed nearly 33,300 trips and 267,000 vehicle miles travelled (VMT) for the combination of EV and HV. Approximately 53\% of the VMT occurred in just 10 counties. For just EVs, there were 9814 unique trips and 64,700 Electric Vehicle Miles Traveled (EVMTs) in total. A further categorization of this revealed that $18 \%$ of these EVMTs were on Interstate roadways and $82 \%$ on non-interstate roads. Proximity analysis of existing DC Fast charging stations in relation to interstate roadways revealed multiple charging deserts that would be most benefited by additional charging capacity. Eleven roadway sections among the 9 interstates were found to have a gap in available DC fast chargers of 50 miles or more. Although the connected vehicle data set analyzed did not include all EV's the methodology presented in this paper provides a technique that can be scaled as additional EV connected vehicle data becomes available to agencies. Furthermore, it emphasizes the need for transportation agencies and automotive vendors to strengthen their data sharing partnerships to help accelerate the adoption of EV and reduce consumer range anxiety with EV. Graphics are included that illustrate examples of counties that are both overserved and underserved by charging infrastructure.
\end{abstract}

\section{Keywords}

Electric Vehicles, Connected Vehicles, Trajectory Data, Driver Behavior, Charging Stations

\section{Introduction}

An estimated 10 million electric vehicles (EV) were on roads in 2020, an increase 
of $41 \%$ for the calendar year. Eighteen of the world's top 20 vehicle manufacturers in 2020 have announced plans to scale up the production of electric vehicles in their fleets [1]. Fifteen countries have publicly announced plans to phase out sales of internal combustion engine (ICE) vehicles in support of zero emissions vehicles [2]. The United States recently set forth a national target for EVs to make up half of all new vehicle sales by the end of this decade [3]. While EVs only account for $4 \%$ of vehicles in the US, their penetration rate has continued to increase approximately $1 \%$ annually since 2017 [4]. It is estimated that EVs will come close to reaching cost parity with ICE vehicles around 2025 that will result in an accelerated transition from ICE to EV [5].

In addition to cost, range anxiety and availability of public charging stations [6] [7] are two of the major barriers currently cited for inhibiting growth of EVs. Furthermore, it is unclear to transportation agencies, consumers, and the private sector where infrastructure usage and charging demand will grow or how fast it will grow. The motivation of this paper is to explore using connected EV data to:

- Characterize differences (or lack of a difference) in EV and ICE operating speeds on Interstates in Indiana;

- Characterize vehicle miles traveled by counties;

- Identify counties that are underserved by charging infrastructure (and perhaps overserved);

- Identify "charging deserts" on major interstates;

- Propose a methodology for evaluating candidate Interstate exits for installing new charging stations.

\section{Literature Review}

A study utilized questionnaire surveys to understand the reasons behind EV and hybrid vehicle (HV) owners in California reverting from an EV purchase and found convenience of charging and limited access to level 2 charging at home as contributing factors to discontinuance [8]. A survey of plug-in electric vehicle (PEV) owners in California in 2016 and 2017 indicated over half of respondents prefer home charging, while results indicated that the use of home, work and public charging locations are an interdependent relationship of charging capacity [9].

Past research has studied the impact of driving characteristics (driving style and speeds) on EV usage and energy consumption using test vehicles in both rural and urban areas indicating aggressive driving of EVs increases the cost to the user by $30 \%$ and causes a marked difference in energy consumption [10]. Multiple energy consumption studies have looked at various factors that may detrimentally impact EV efficiency and range including road type, auxiliary loads (such as HVAC systems), driving at higher speeds, acceleration profiles, increased vehicle cross-sectional area and ambient environment [11] [12] [13]. Research has established that battery electric vehicles have significant energy savings for low speed drives with frequent stops, and observe substantial energy consumption at highway speeds [14]. 
An EV usage and planning study completed on six EVs deployed in Athens, GA found most EVs were charged continuously within 3 hours and $80 \%$ of all trips were less than 10 miles [15]. EV charging infrastructure planning research has utilized long-term traffic flow predictions and public transportation datasets to estimate optimal future charging infrastructure plans [16]. A study looked at spot traffic counts in Western Australia coupled with an assumed EV penetration rate of $1 \%$ to select sites for future DC Fast charging stations using the criterion of reliability, accessibility and availability of amenities and services [17]. Various simulation-based approaches have been employed in the past for EV fast charging infrastructure planning using simulated trajectories and charging behavior assumptions [18], urban mobility simulations that minimize EV energy consumption [19], as well as mathematical programming models factoring in user convenience and grid connections for low penetration levels of 5\% [20]. Data obtained from fast charging stations in Ireland observed 0.18 charges per day per EV user at home and 0.06 charges per day per EV user in public charging locations, thus reinforcing the need for more strategically placed fast charging stations to incentivize more usage in non-peak grid demand times [21].

Past research has heavily focused on factors affecting EV range and charging behavior and patterns on a user level. While most of the above studies utilized floating car data, spot traffic counts, mathematical programming or simulation modeling, very few studies have looked at real world connected vehicle data collected from EVs and HVs to evaluate driver behavior and usage as it relates to charging infrastructure on a macroscopic, statewide level. Our study aims to bridge this gap by using connected vehicle data for a 1-week period in Indiana for EVs and HVs.

\section{Connected Vehicle Data}

Indiana ingests over 10 billion connected vehicle records per month from a combination of EV and ICE, with penetration of roughly $4 \%$ of all vehicles [22]. The charging standard for the EV vehicles analyzed is the SAE J1772 and Combined Charging System (CCS) standard. This study looked at a one-week period from July 12-18, 2021 to evaluate EV and HV usage patterns as they relate to existing charging infrastructure.

Connected vehicle data utilized in this study is made up of individual journey waypoints recorded at a 3-second fidelity. Each data record contains the following attributes: Geolocation, speed, heading, timestamp, an anonymized unique trajectory identification number and a vehicle classification code. This vehicle classification code was then cross referenced with the National Highway Traffic Safety Administration's (NHTSA) Product Information Catalog Vehicle Listing (vPIC) Application Programming Interface (API) [23] to obtain the electrification level associated with it. If the electrification level obtained is 'BEV (Battery Electric Vehicle)', the vehicle classification code and subsequently the associated waypoint is flagged as belonging to an electric vehicle. A similar classification process is followed for Hybrid Vehicles as well (Figure 1). 


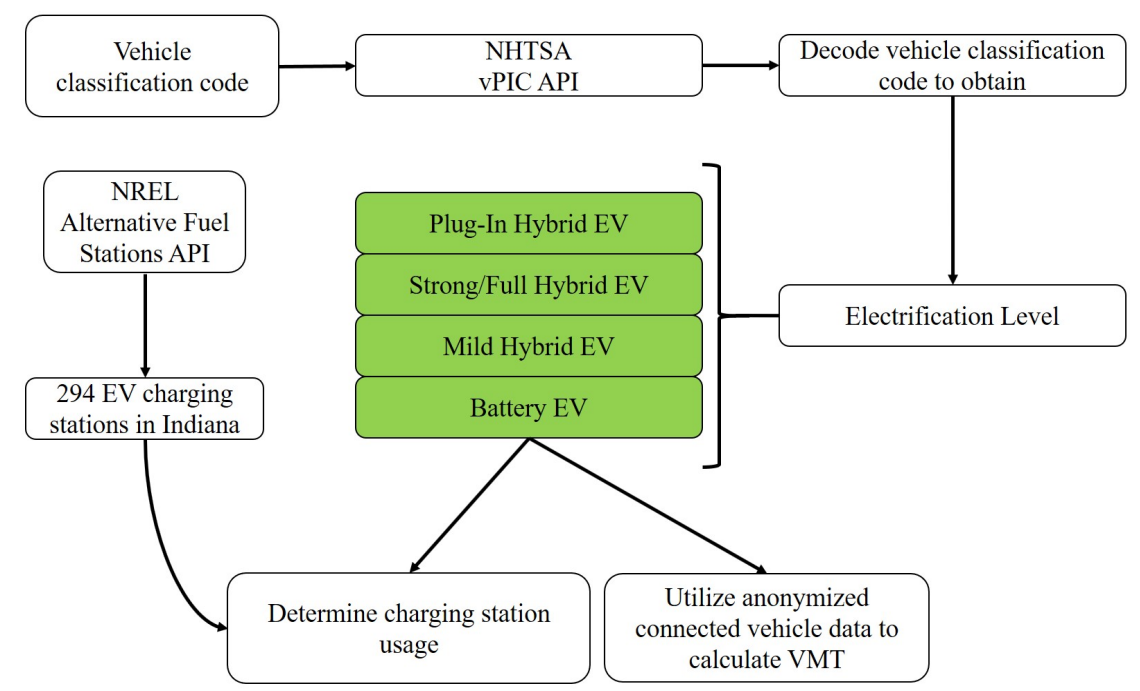

Figure 1. Methodology for decoding vehicle classification code to isolate EV and HV connected vehicle data.

Nearly 2.65 million waypoints were thus found for EVs for the week of July 12-18, 2021 spread over 9800 unique trips for the state of Indiana. Correspondingly, 7.74 million waypoints were obtained for HVs for the same week spread over 23,000 unique trips. A spatial representation of these EV and HV waypoints has been shown in Figure 2(a) and Figure 2(b) respectively. In comparison, over 7.54 million unique trips were found for ICE vehicles (ICEV) for the same period. The majority of the EV and HV coverage is concentrated in metropolitan areas.

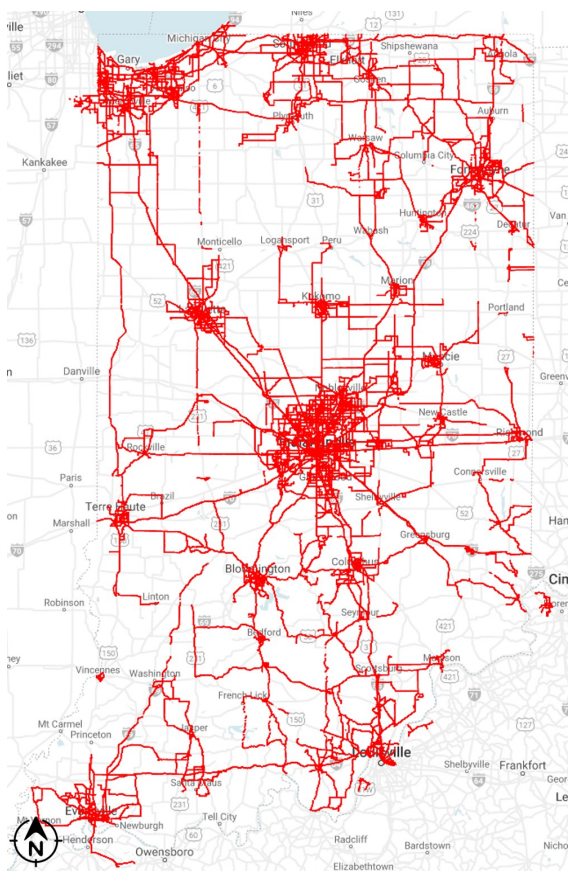

(a)

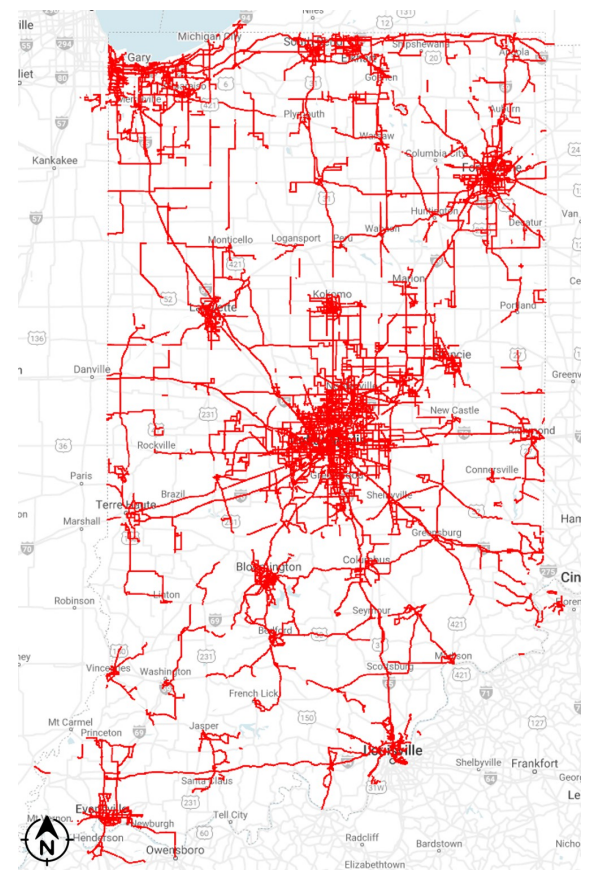

(b)

Figure 2. Electric and hybrid vehicle trails in Indiana (July 12-18, 2021). (a) 64,700 EVMTs in Indiana; (b) 202,000 HVMTs in Indiana. 
Of the 92 counties in the state of Indiana, vehicle miles traveled (VMT) totals were computed for both EVs and HVs by matching each individual waypoint to the county it was recorded in. A spatial representation of these EVMTs and HVMTs in terms of percentage of the total VMT (EVMT + HVMT) by the county have been shown in Figure 3(a) and Figure 3(b). A tabular representation of the top 10 counties with the highest combined totals of EVMT and HVMT is shown in Table 1. Marion (callout i), Hamilton (callout ii) and Lake (callout iii) counties account for the highest EVMTs while Marion, Hamilton and Allen (callout iv) counties observed the highest HVMTs. Marion county had the highest vehicle miles traveled for EVs and HVs overall.

$$
\begin{aligned}
& \text { Percent of total EVMT (miles) } \\
& \begin{array}{l}
0 \%-2 \% \\
2 \%-4 \% \\
4 \%-6 \% \\
6 \%-8 \% \\
8 \%-10 \% \\
10 \%-12 \% \\
12 \%-14 \% \\
14 \%-16 \%
\end{array}
\end{aligned}
$$

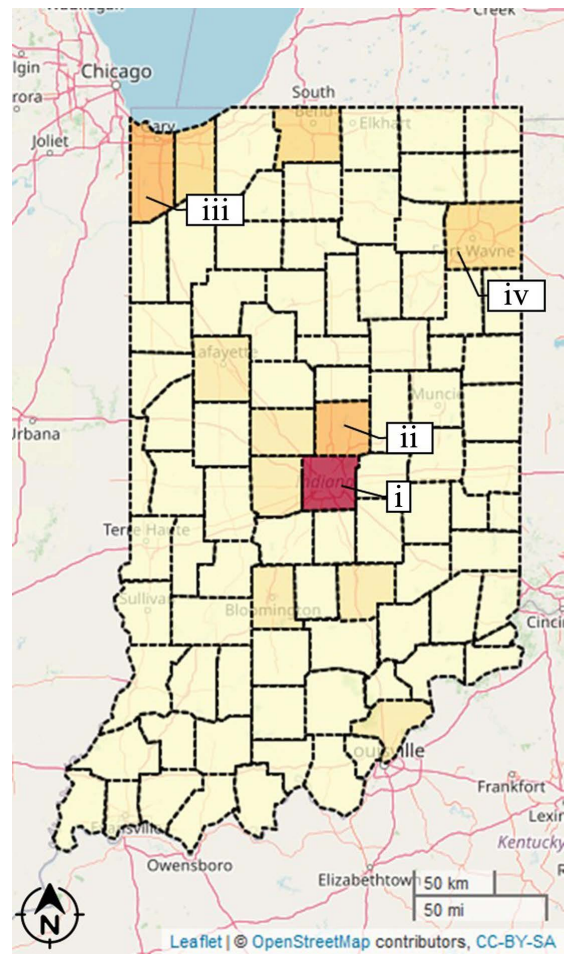

(a)

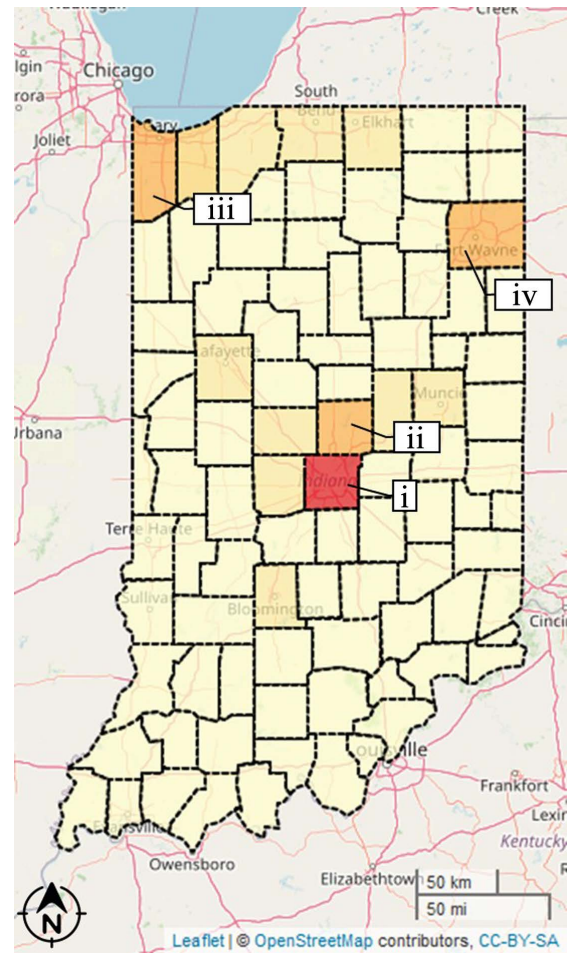

(b)

Figure 3. EVMTs and HVMTs aggregated by Indiana County (July 12-18, 2021). (a) EVMTs aggregated by County; (b) HVMTs aggregated by County. 
Table 1. Top 10 Indiana counties with highest totals of EVMT and HVMT (July 12-18, 2021).

\begin{tabular}{cccc}
\hline County & EVMT (miles) & HVMT (miles) & Total (miles) \\
\hline Marion & 9557 & 27,980 & 37,537 \\
Hamilton & 4625 & 15,994 & 20,619 \\
Allen & 3067 & 15,085 & 18,152 \\
Lake & 4294 & 12,862 & 17,156 \\
Porter & 2693 & 8223 & 10,916 \\
St. Joseph & 2899 & 5820 & 8719 \\
Hendricks & 1865 & 5447 & 7312 \\
Tippecanoe & 2274 & 4910 & 7184 \\
Monroe & 1983 & 5010 & 6993 \\
Madison & 916 & 5353 & 6269 \\
\hline
\end{tabular}

\section{Electric and Hybrid Vehicle Miles Traveled by Roadway}

Using linear referenced sections of the roadway on all Indiana interstates at approximately 0.1 -mile fidelity, each EV and HV waypoint was cross-referenced and matched to an interstate route with a direction of travel. This enabled the computation of summary statistics for EVs and HVs in terms of percent of vehicle miles traveled (VMT) on interstate corridors and non-interstate roadways (Figure 4). Approximately $18 \%$ of EVMTs occur on interstate roadways and $24 \%$ of HVMTs occur on interstates. A further categorization of EVMTs and HVMTs was performed for individual routes for 11 interstate corridors around the state. A stacked bar representation shown in Figure 4(c) clearly illustrates the north-south interstate route I-65 and I-69 seeing the most EV and HV traffic in addition to substantial EV and HVMT on the I-465 loop around Indianapolis.

Using the route-by-route breakdown of EVMTs for Indiana Interstates obtained earlier, the top ten 1-mile interstate segments with highest EVMTs are shown graphically and on an Indiana map in Figure 5(a) and Figure 5(b) respectively. Eight of the top 10 segments were found to be in urban areas primarily on or near the I-465 beltway around Indianapolis which observes daily commuter traffic. Additional segments on I-94 in northwest Indiana see significant usage potentially owed to traffic commuting to and from Illinois. These high usage sections could be potential early deployment sites for additional charging stations and/or in-pavement wireless charging [24].

\section{Interstate Operating Speeds of Electric and Hybrid Vehicles}

Average Speeds of EVs and HVs, and ICEVs that traversed on I-65 (chosen due to highest EVMTs and HVMTs recorded among all interstates) were evaluated for the week of July 12-18, 2021. Median EV and HV speeds were found to be 68.7 and $71.6 \mathrm{mph}$ respectively, with ICEVs operating at a median speed of 72.3 mph. 


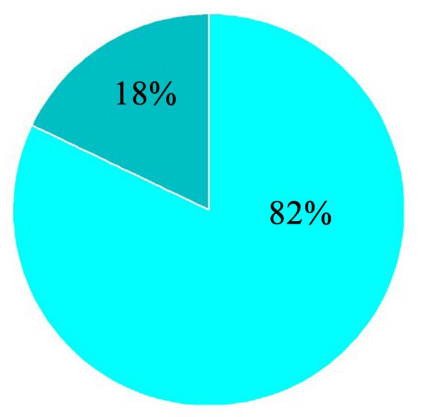

Interstate EVMTs

Non-Interstate EVMTs

(a)

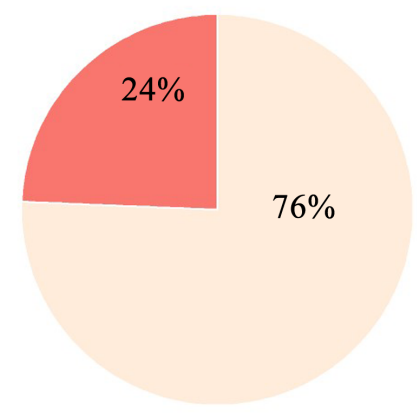

Interstate HVMTs

Non-Interstate HVMTs

(b)

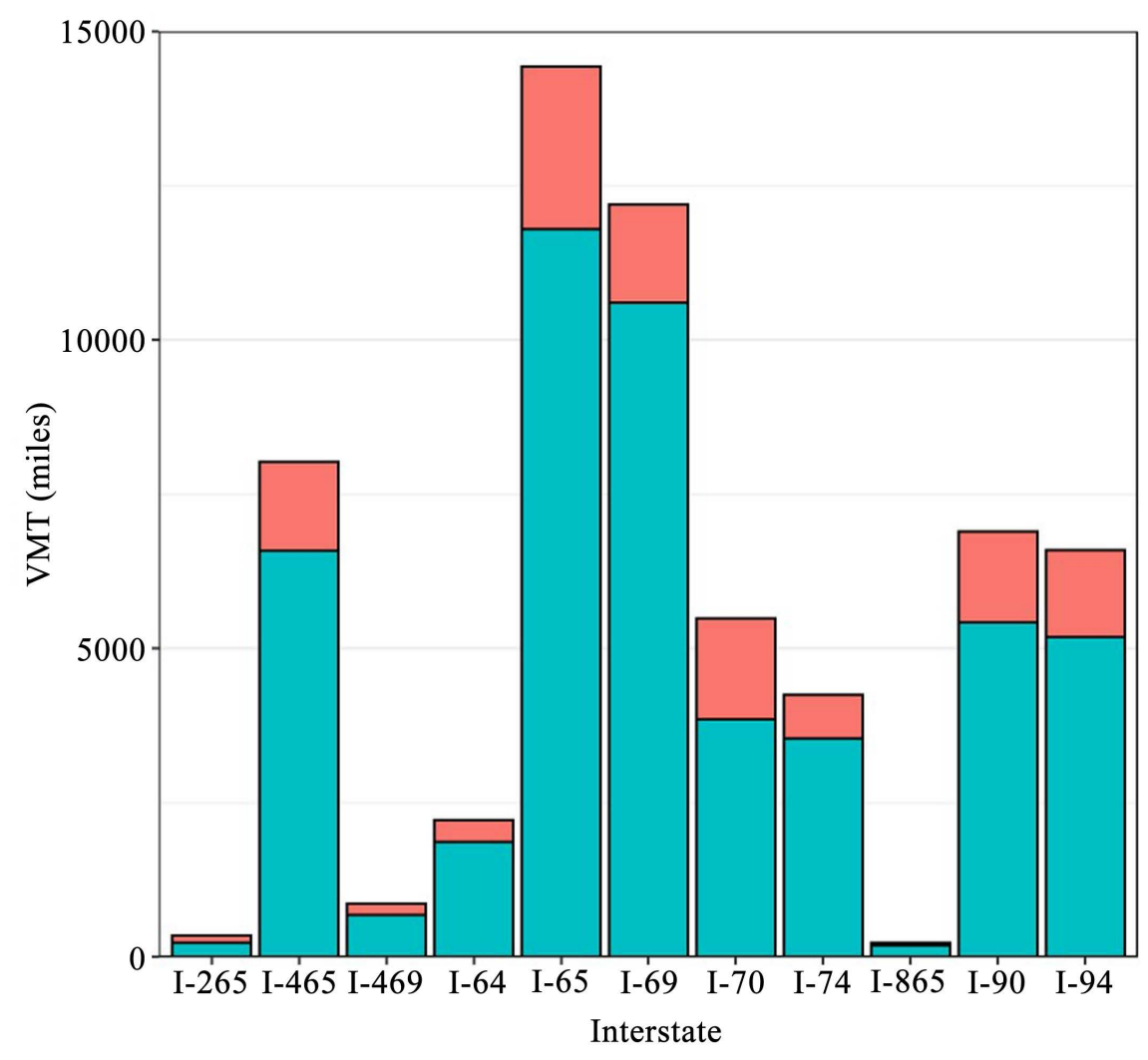

Vehicle Type $\square$ EV $\square$ HV

(c)

Figure 4. VMTs categorized by roadway, interstate routes (July 12-18, 2021). (a) EVMTs categorized by roadway; (b) HVMTs categorized by roadway; (c) Interstate VMTs categorized by EVs and HVs.

Figure 6 shows a cumulative frequency distribution plot of uncongested vehicle speeds (speeds above $45 \mathrm{mph}$ ) for I-65. A separate frequency line has been used for each of the EV, HV and ICEV vehicle classes for ease of comparison.

From Figure 6, one can see that the distribution of ICE vehicle speeds is higher than both HV and EV. In fact, there is approximately a $3 \mathrm{mph}$ difference 


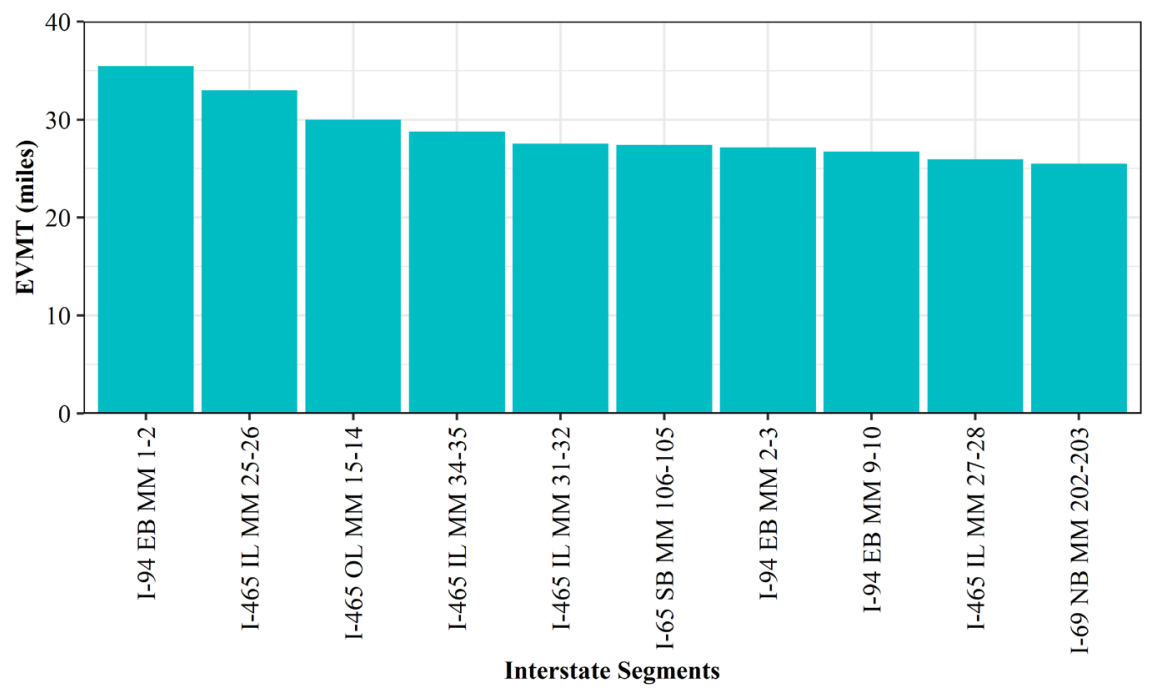

(a)

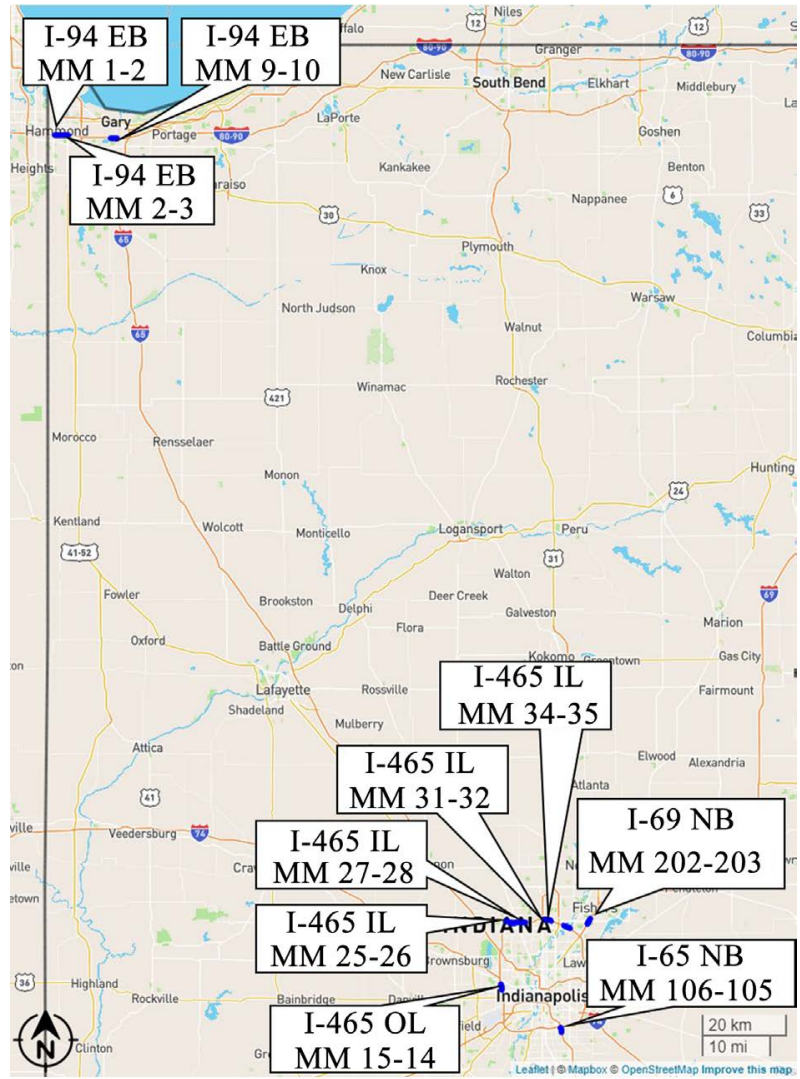

(b)

Figure 5. Interstate segments with highest EVMTs (July 12-18, 2021). (a) Top 10 interstate segments with highest EVMTs; (b) Statewide map of top 10 interstate segments with highest EVMTs.

in median speeds between ICE and EV. Some of this may be due to range anxiety concerns by EV operators resulting in them driving at lower speeds to conserve battery charge and/or different driving styles of ICE and EV consumers. 


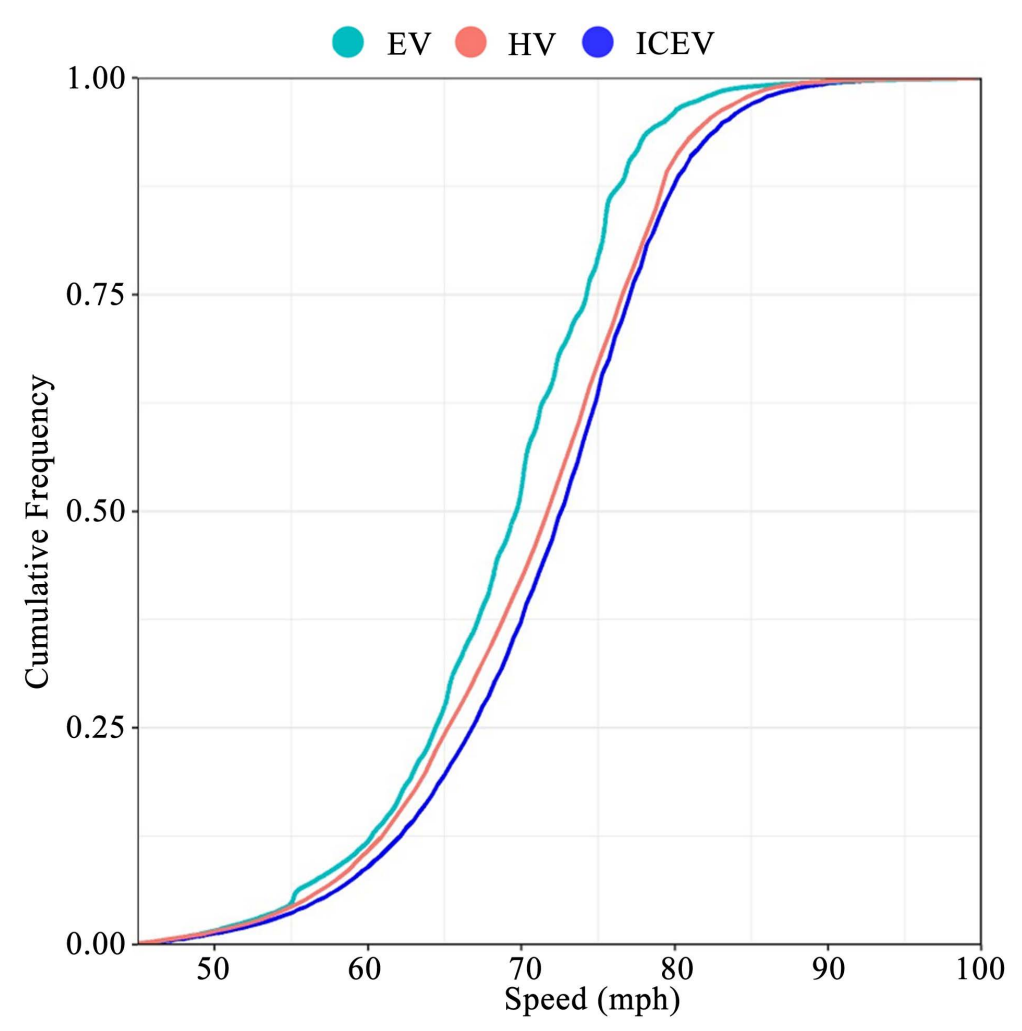

Figure 6. Cumulative frequency distributions of EV, HV and ICEV uncongested speeds for I-65 (July 12-18, 2021).

\section{Evaluating EV Charging Infrastructure}

Using the National Renewable Energy Laboratory's (NREL) alternative fuel stations API [25], geolocation data and multiple other pertinent attributes including number of charge points were obtained for 294 electric charging stations in Indiana. Among these, 270 were found to be level 2 capable (Figure 7(a)) and 24 stations were found to be capable of providing DC Fast Charging (Figure 7(b)). Fast charging is a critical need for long-distance driving, especially for travel on long stretches of limited access roadways such as interstate corridors. Level 2 charging was observed to be spread out across the state with clusters in the Gary, South Bend, Fort Wayne and Indianapolis regions. DC Fast charging is however more sparsely distributed with few in the north-central and southwest region.

\subsection{Charging Station Usage}

With rising adoption rates of $\mathrm{EV}$ and $\mathrm{HV}$, a clear and present concern for $\mathrm{EV}$ owners as well as the private sector is charging station capacity. With limited charging infrastructure and charging spots at each station, the adoption rate of EVs could soon possibly surpass the ability of existing infrastructure to serve all $\mathrm{EV}$ owners if the growth of infrastructure does not keep pace. Owing to this, an analysis of charging station usage is needed to compute number of unique uses per day to look at charging patterns. A DC Fast charging station in South Bend, Indiana was utilized for this analysis as shown in Figure 8(a). 


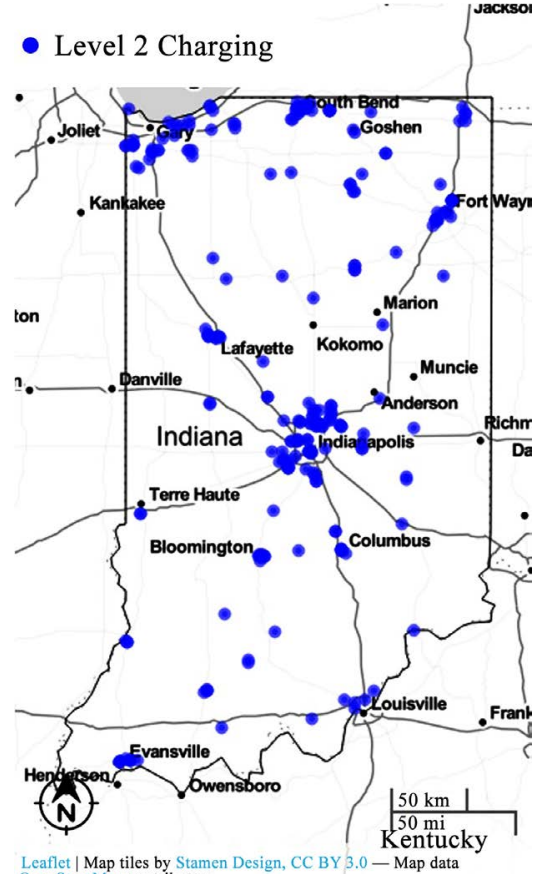

Leaflet | Map tiles by Stame
OpenStreeMap contributors

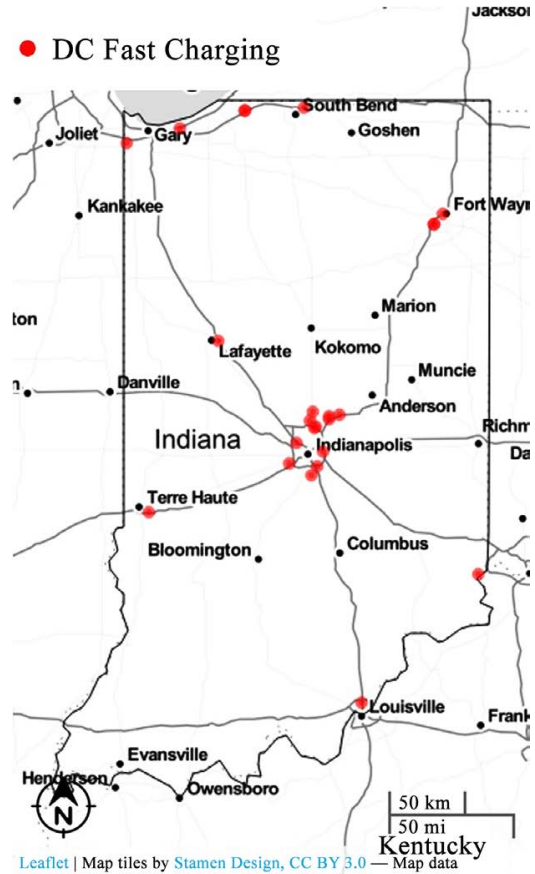

(b)

Figure 7. Level 2 and DC fast charging infrastructure in Indiana [25]. (a) 270 level 2 charging stations; (b) 24 DC fast charging stations.

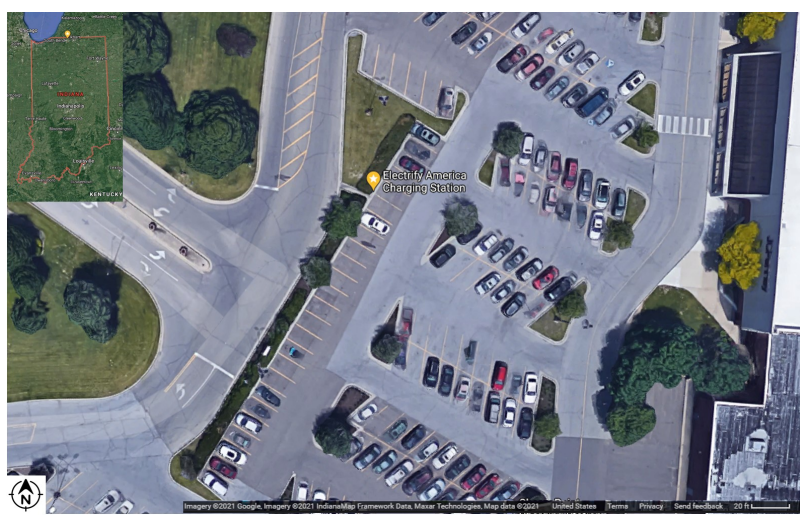

(a)

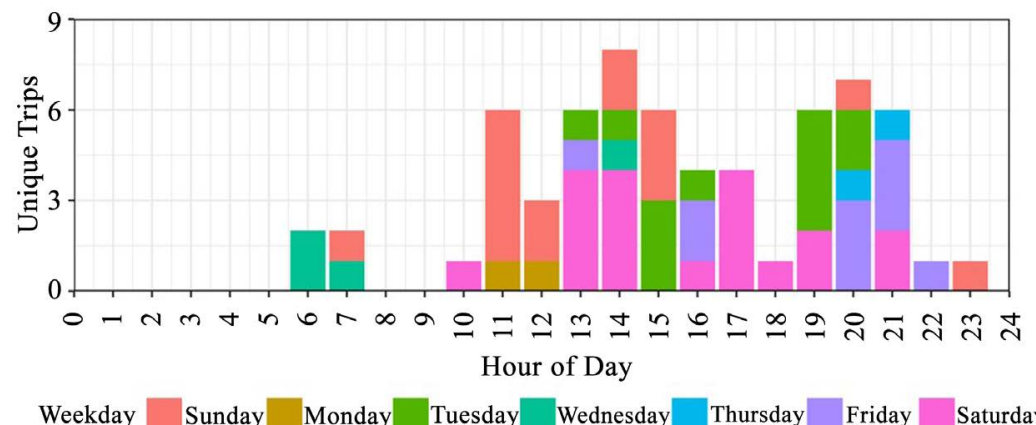

(b)

Figure 8. Charging station usage (June 1-July 27, 2021). (a) DC fast charging station (South Bend, Indiana); (b) Usage by hour of day and day of week. 
A spatial polygon was drawn around all of the charging spots at this station. EV waypoint geolocations for a nearly 2-month period of June 1-July 27, 2021 were then cross-referenced with this polygon to detect those waypoints that coincided directly with either of the charging spots. Using the obtained intersection of data, a temporal profile of unique EV trips visiting this charging station has been shown by the illustration in Figure 8(b) categorized by day of week and hour of day. The hours of 2 PM and 8 PM specifically show up as peak charge times with the weekend period of Friday, Saturday and Sunday appearing to be the preferred time to charge. While this analysis only provides an initial look at charging patterns at one station, this methodology is easily scalable to any charging station irrespective of location which makes it a valuable tool for EV stakeholders.

Using a similar methodology as shown above, the top ten most utilized EV charging stations were found for the state of Indiana, 9 of which were level 2 capable and 1 provided DC fast charging capability (ranked 7). A majority of these stations were found to be in urban areas near Indianapolis, South Bend and Columbus and have also been shown on an Indiana county map along with their ranks called out in Figure 9.

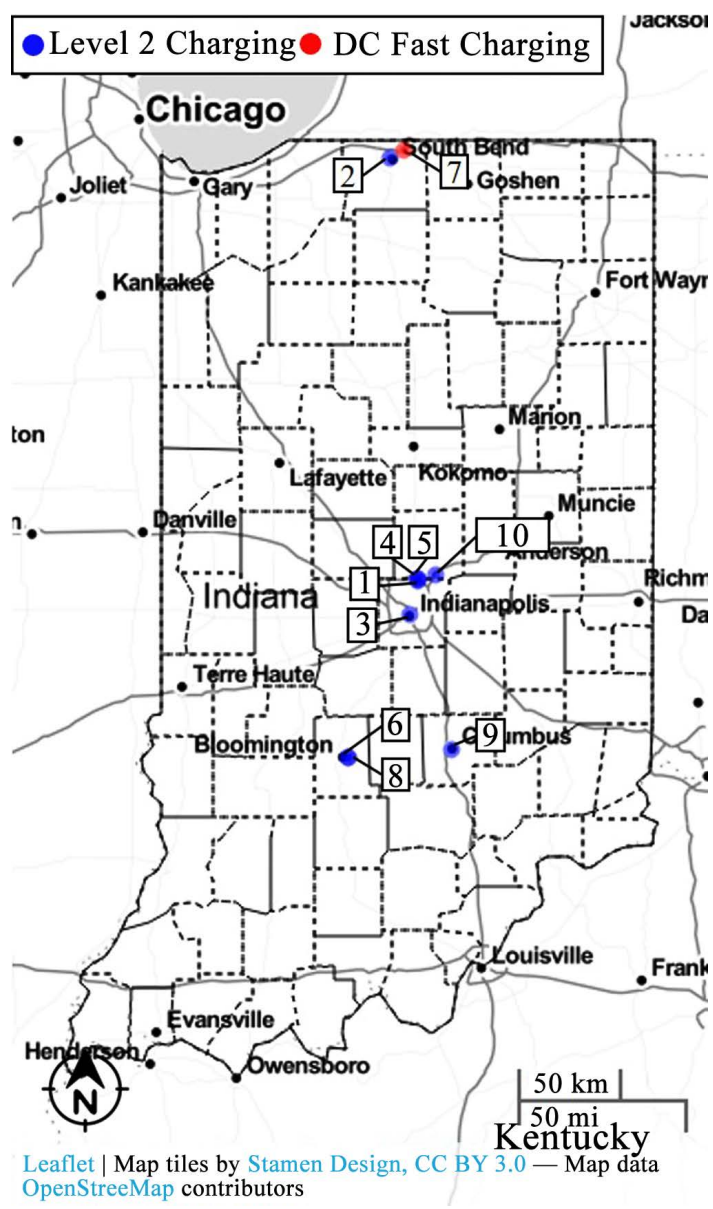

Figure 9. Top 10 utilized EV charging stations in Indiana called out by rank (July 12-18, 2021). 
For all 92 counties in Indiana, the number of charging stations and the number of charge points at all stations were obtained. A linear relationship was established between VMTs for EVs and HVs versus the number of charge stations as well as the number of charge points available per county. This distinction between charge points and charge stations is needed as the number of charge stations in a county alone may not reflect the true charging capacity owing to multiple charge points available at each station. A scatter plot along with a predicted linear relationship line between number of charge stations, EVMTs and HVMTs by Indiana county has been shown in Figure 10(a). A similar plot showing a relationship with number of charge points is depicted in Figure 10(b).

- EV OHV

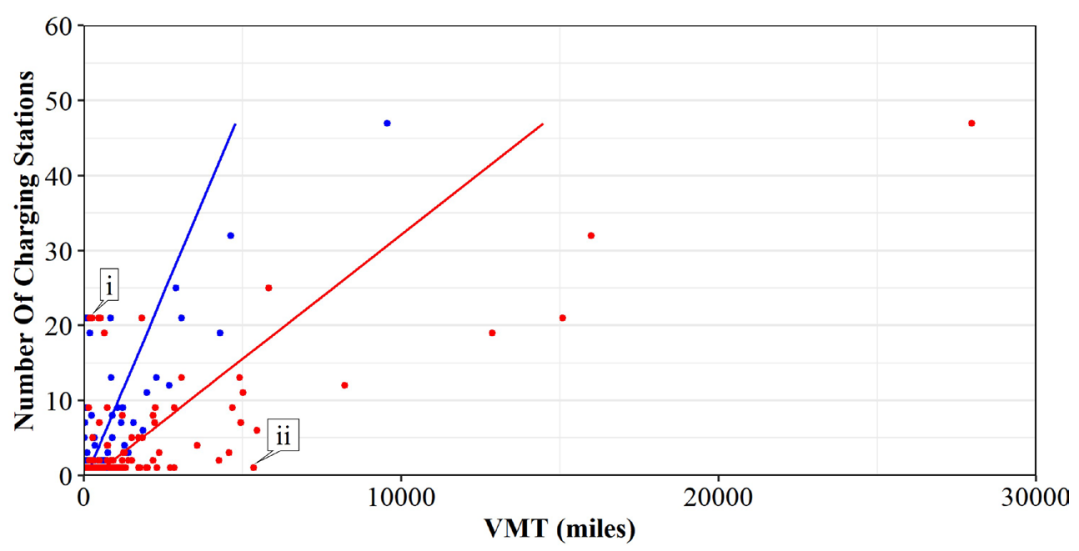

(a)

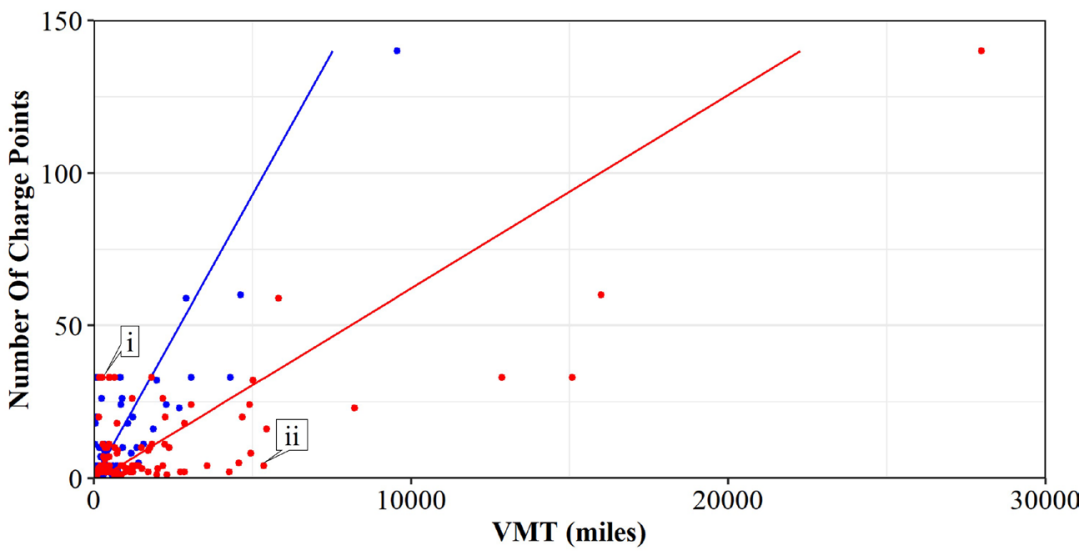

(b)

Figure 10. Relationship between charging locations and VMT by Indiana county (July 12-18, 2021). (a) Count of EV charging stations vs. EVMT and HVMT by Indiana county; (b) Count of EV charging points vs. EVMT and HVMT by Indiana County.

- Clusters near the y-axis pointed to by callouts i on Figure 10(a) and Figure 10 (b) indicate overserved counties in the state where a high number of charging stations and charge points are available however minimal EVMTs and HVMTs are observed. 
- Clusters near the $\mathrm{x}$-axis pointed to by callouts ii on Figure 10(a) and Figure 10(b) indicate underserved counties in the state where there is a high EVMT or HVMT, but little charging infrastructure.

These visualizations may be helpful to government and private sector planners in providing a first look at determining which geographical locations in particular are over or underserved and allocating resources and investment accordingly.

\subsection{Sensitivity Analysis for DC Fast Charging Station Proximity to Interstates}

As fast charging is essential for planning long distance routes, availability of fast charging stations near high-speed interstate corridors is essential to assuage range anxiety. Using the geolocations of the 24 DC Fast charging stations in Indiana [25], a proximity analysis was conducted to determine the closest interstate roadway to each station within a specified radius. The results of a sensitivity analysis wherein the specified radius was increased in 1-mile steps are shown in Table 2. 75\% of all DC Fast charging stations were found to be within 1-mile of an interstate corridor while $96 \%$ of all DC Fast charging stations were within 6 miles of an interstate.

Table 2. Proximity of DC fast charging stations to Indiana interstates.

\begin{tabular}{ccc}
\hline Radius (mi) & $\begin{array}{c}\text { Number of DC Fast Charging } \\
\text { Stations within the radius }\end{array}$ & $\begin{array}{c}\text { Percentage of DC Fast Charging } \\
\text { Stations within the radius }\end{array}$ \\
\hline 1 & 18 & $75 \%$ \\
2 & 20 & $83 \%$ \\
3 & 21 & $88 \%$ \\
4 & 22 & $92 \%$ \\
5 & 22 & $92 \%$ \\
6 & 23 & $96 \%$ \\
7 & 23 & $96 \%$ \\
8 & 23 & $96 \%$ \\
9 & 23 & $96 \%$ \\
State of Indiana & 24 & $100 \%$ \\
\hline
\end{tabular}

\section{Charging Deserts on Interstate Routes}

Using the results of the sensitivity analysis from above, the closest interstate roadways were found within 1-mile of each of the 18 stations. These limits were subsequently utilized to introduce the concept of a fast "charging desert," which indicates long segments of interstate without a DC Fast charging station available within a 1-mile threshold. A statewide summary of charging segments and deserts on nine interstate routes is shown in Figure 11(a). Each interstate is broken up into segments at either end of which is either a charging station, route endpoint, or the state boundary line, however a fast-charging station is not found in the interior of the segment. It was assumed that a 50-mile length threshold for a fast charging desert would be significant enough to add to range an- 
xiety concerns, as the average late-model production EV can travel about 3.4 miles per kilowatt-hour [26] and a typical level 2 charger outputting 6.6 kilowatts, thereby potentially adding up to about one hour to a trip if resorted to a level 2 charger. Each such 50-mile or longer segment is termed a desert and has been illustrated in Figure 11(b) highlighting multiple long fast charge gaps on Indiana's interstates, from Lafayette to Gary on I-65, Evansville to Indianapolis on I-69 and Terre Haute to Indianapolis on I-70 to name a few.

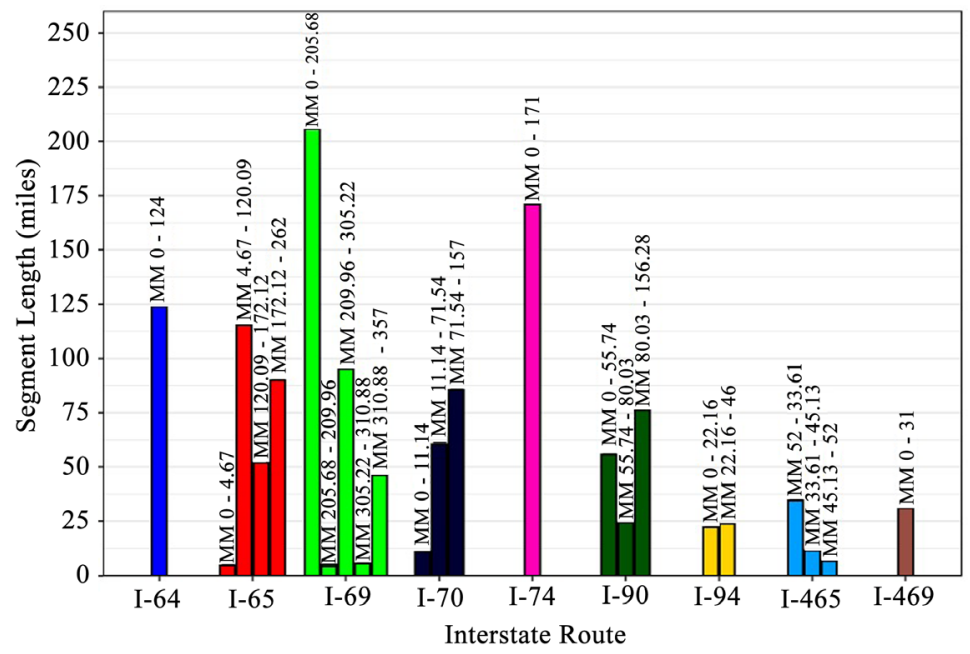

(a)

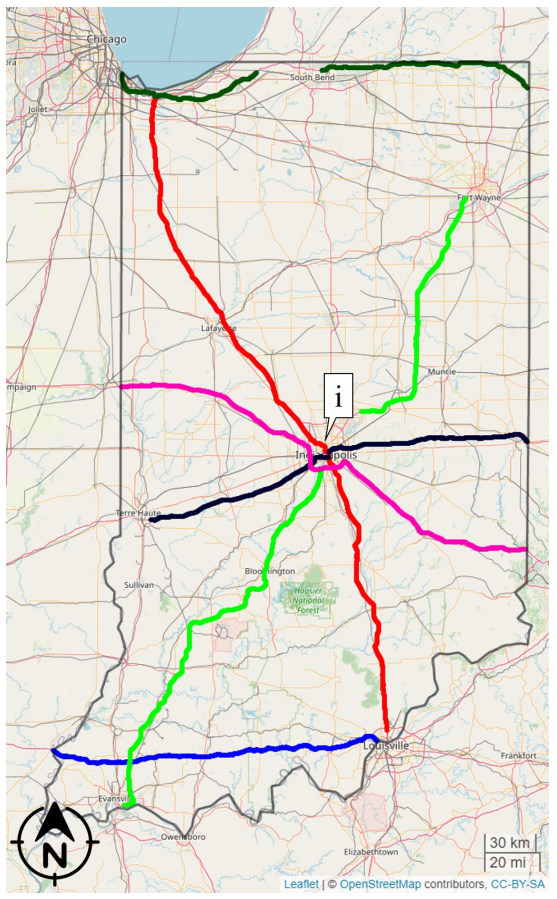

(b)

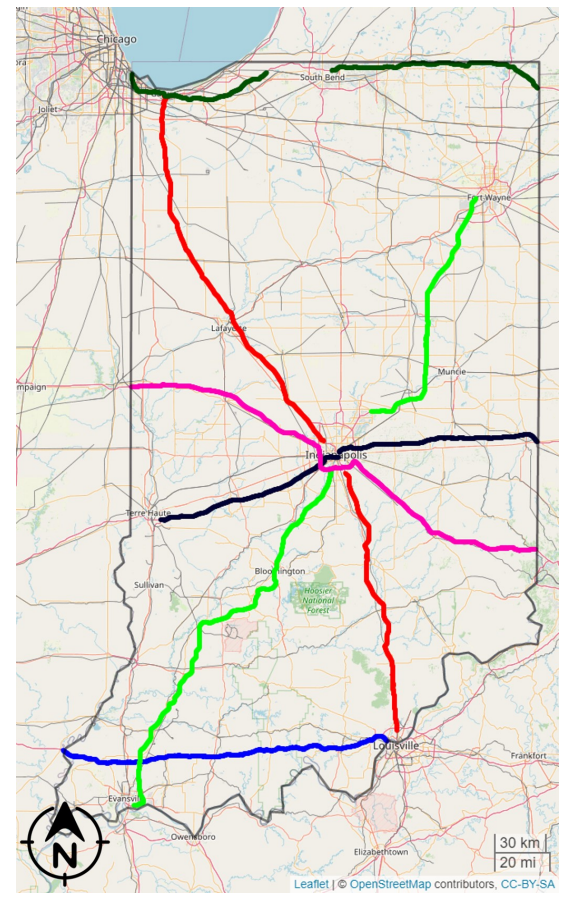

(c)

Figure 11. Segment lengths on Indiana interstates without a DC fast charging station (Fast charge deserts). (a) DC fast charging availability segments on Indiana interstates; (b) DC fast charging deserts longer than 50 miles (no station within 1 mile of interstate); (c) DC fast charging deserts longer than 50 miles (no station within 5 miles of interstate). 
To spatially visualize the sensitivity of the 1-mile threshold, a corresponding desert map has been shown in Figure 11(c) with a 5-mile threshold where the I-65 desert south of Indianapolis is shorter owing to a DC fast charging station found within a 5-mile radius. Callout (i) on Figure 11(b) shows the original longer desert on I-65 which reduces in length when the proximity threshold for charging stations is changed from 1 mile to 5 miles.

For a detailed look at each interstate, start and end mile markers $(\mathrm{mm})$ for each charging segment and whether it is a potential desert or not are provided in Table 3. For example, I-65 consists of three charging deserts, one between MM 4 and MM 120, the second between MM 120 and MM 172 and the third between MM 172 and MM 262. Eleven fast charging deserts in total were found across 9 interstate routes in Indiana.

Table 3. Summary of charging segments and deserts on Indiana interstates (no station within 1 mile of interstate).

\begin{tabular}{|c|c|c|c|c|c|}
\hline \multirow{2}{*}{ Interstate } & \multirow{2}{*}{$\begin{array}{l}\text { Total Length } \\
\text { (mi) }\end{array}$} & \multicolumn{3}{|c|}{ Fast Charging Availability Segments } & \multirow{2}{*}{ Potential Desert } \\
\hline & & Start MM & End MM & Length (mi) & \\
\hline \multirow{3}{*}{$\mathrm{I}-465$} & \multirow{3}{*}{53} & 52.0 & 33.6 & 34.6 & \\
\hline & & 33.6 & 45.1 & 11.5 & \\
\hline & & 45.1 & 52.0 & 6.9 & \\
\hline $\mathrm{I}-469$ & 31 & 0.0 & 31.0 & 31.0 & \\
\hline I-64 & 124 & 0.0 & 124.0 & 124.0 & Yes \\
\hline \multirow{4}{*}{$\mathrm{I}-65$} & \multirow{4}{*}{262} & 0.0 & 4.7 & 4.7 & \\
\hline & & 4.7 & 120.1 & 115.4 & Yes \\
\hline & & 120.1 & 172.1 & 52.0 & Yes \\
\hline & & 172.1 & 262.0 & 89.9 & Yes \\
\hline \multirow{5}{*}{ I-69 } & \multirow{5}{*}{357} & 0.0 & 205.7 & 205.7 & Yes \\
\hline & & 205.7 & 210.0 & 4.3 & \\
\hline & & 210.0 & 305.2 & 95.2 & Yes \\
\hline & & 305.2 & 310.9 & 5.7 & \\
\hline & & 310.9 & 357.0 & 46.1 & \\
\hline \multirow{3}{*}{$\mathrm{I}-70$} & \multirow{3}{*}{157} & 0.0 & 11.1 & 11.1 & \\
\hline & & 11.1 & 71.5 & 60.4 & Yes \\
\hline & & 71.5 & 157.0 & 85.5 & Yes \\
\hline $\mathrm{I}-74$ & 171 & 0.0 & 171.0 & 171.0 & Yes \\
\hline \multirow{2}{*}{ I-94 } & \multirow{2}{*}{46} & 0.0 & 22.2 & 22.2 & \\
\hline & & 22.2 & 46.0 & 23.8 & \\
\hline \multirow{3}{*}{ I-90 } & \multirow{3}{*}{156.28} & 0.0 & 55.7 & 55.7 & Yes \\
\hline & & 55.7 & 80.0 & 24.3 & \\
\hline & & 80.0 & 156.3 & 76.3 & Yes \\
\hline
\end{tabular}

\section{Evaluating EV Usage of Interstate Exits for Charging Locations}

Having identified the significant fast charge gaps on interstates as shown in ear- 
lier sections, the opportunity provided to planners would be to decide which interstate exits to place additional charging infrastructure. It can be assumed that the most heavily utilized exits, irrespective of vehicle class, would serve as the ideal locations to reinforce with charging capacity.

Without tracking user activity patterns over an entire trip, our methodology makes use of the vehicle classification code which represents the make and model of a vehicle in order to look at outflows and inflows on the exit and entry ramps respectively at a chosen interstate location by defining a time threshold ranging from 30 to 90 minutes. We thus ensure anonymity by not capturing any stopping patterns from the connected vehicle data.

Figure 12 shows exit 68 on I-65 NB (near the midway point on I-65 charging desert MM 4-120 from Table 3) near Columbus, Indiana to illustrate this analysis technique. Connected vehicle waypoints shown in blue indicate those trips traveling through on I-65 without taking the exit, red indicate those exiting (callout ii) and green indicate trips entering I-65 NB (callout i) at the same location using one of two entry ramps. All EV, HV, and ICEV waypoints were used for this analysis.

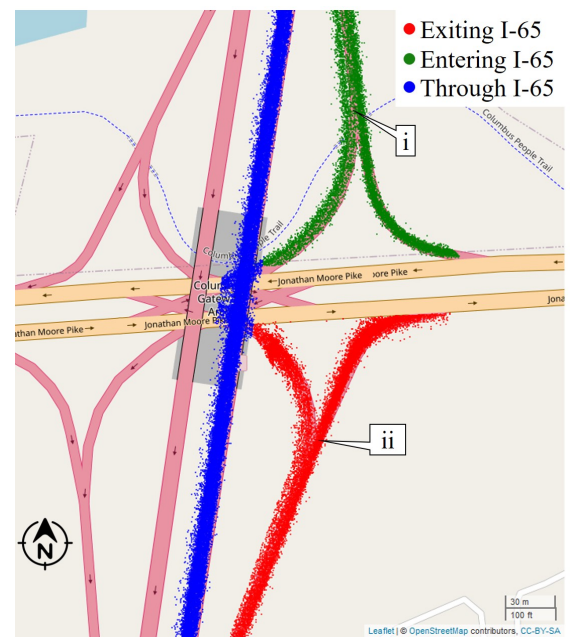

Figure 12. I-65 NB through, exiting and entering trajectory samples at I-65 Exit 68 (July $12-18,2021)$

Once trips have been categorized as exiting, entering and through, each vehicle classification code from an exiting trip is matched with all vehicle classification codes from entering trips that are seen on the entry ramps within 30-minutes of the exiting trip. If a match is found, that particular trip is flagged as one that took a short break at the exit under consideration.

Using the methodology defined above, the analysis was conducted for a 1-week period from July 12-18, 2021 for MM 68 exclusively for the northbound direction of travel. Nearly 8.5 million connected vehicle records from over 61,000 unique trips were observed near this exit. Out of these, approximately 1.5 million records were found to be traveling northbound on I-65 spread over 
11,800 unique trips. The results of the analysis conducted on these records have been shown in Table 4.

Table 4. Summary table of time threshold sensitivity and number of journeys taking a short break at I-65 exit 68 categorized by vehicle type, July 12-18, 2021.

\begin{tabular}{cccc}
\hline \multirow{2}{*}{ Time Threshold (minutes) } & \multicolumn{3}{c}{ Journeys taking a short break } \\
\cline { 2 - 4 } & EV & HV & ICEV \\
\hline 30 & 0 & 2 & 260 \\
60 & 0 & 2 & 364 \\
90 & 0 & 2 & 414 \\
\hline
\end{tabular}

We thus see 262 trips (30-min threshold), 366 trips (60-min threshold) and 416 trips (90-min threshold) taking a short break at exit 68 over a 1-week period. This represents at the very least nearly $2 \%$ of trips taking a short break at this exit. The scalable nature of this methodology allows practitioners and researchers to apply similar techniques throughout an interstate to find the most utilized exits on a corridor and subsequently plan the placement of additional EV charging infrastructure accordingly so as to provide a good charging level of service to the $\mathrm{EV}$ and $\mathrm{HV}$ motoring public.

\section{Conclusions and Future Opportunities}

This study used one week of connected vehicle trajectory data in Indiana to analyze EV and HV usage patterns. Nearly half of all VMTs for EVs and HVs were seen in just the top 10 counties. A spatial analysis highlighted multiple Indiana counties near Indianapolis with the highest EV ownership and usage, followed by Allen County in Northeast Indiana and Lake County in Northwest Indiana. (Figure 3, Table 1). Out of nearly 11,600 EVMTs and 49,200 HVMTs on Indiana interstates, I-65 had the largest EV traffic with 2631 EVMTs (Figure 4(c)). In general, the average speeds of the EVs were close, but slightly less than HV and ICE, indicated by the left shift on the EV speed distributions (Figure 6).

A graphic of charge stations and charge points versus VMTs for EVs and HVs on a county-by-county basis was used to identify underserved and overserved counties where the charging infrastructure does not match travel demand and vice versa (Figure 10).

Subsequently, a methodology was presented to evaluate the percent of EV, HV and Non-EV trips exiting for short breaks at interstate exits. This methodology can be used to obtain the most commonly utilized Interstate exits by EVs to further aid in decisions involving the deployment of charging infrastructure to address any under or overserving issues.

There are 24 DC Fast charging stations spread around the state, and the majority of them (75\%) are accessible within 1 mile of interstate roadways in Indiana (Table 2). The concept of a "fast charging desert" was introduced to identify long interstate segments that lacked DC Fast charging stations within 1 mile of 
the Interstate. The study found 11 interstate segments, over 50 miles in length that lacked adjacent DC Fast charging stations. These segments have been shown in Figure 11 and Table 3. Methods to analyze charging station usage (Figure 8) coupled with this analysis of charge gaps can together provide a good overview of existing charging infrastructure performance for stakeholders.

In addition to examining opportunities for fast charging stations, it is also important to look at locations that might be viable for wireless EV charging. This study identified ten 1-mile interstate segments observing the highest EVMTs (Figure 5) as an early screening for further evaluation [24]. Not surprisingly, they were near urban areas.

In conclusion, an important question all EV stakeholders are currently facing is balancing investment in areas that have growing EV usage versus investing in underserved areas in an effort to stimulate demand. We believe the performance measures and visualizations put forth in this paper will be important tools for public agencies and private sector partners to use to help inform future policies and investments.

\section{Acknowledgements}

Trajectory data between June $1^{\text {st }}$ and July $27^{\text {th }}, 2021$ used in this study, was provided by Wejo Data Services Inc. This work was supported in part by the National Science Foundation and the Joint Transportation Research Program administered by the Indiana Department of Transportation and Purdue University. The contents of this paper reflect the views of the authors, who are responsible for the facts and the accuracy of the data presented herein, and do not necessarily reflect the official views or policies of the sponsoring organizations. These contents do not constitute a standard, specification, or regulation.

\section{Conflicts of Interest}

The authors declare no conflicts of interest regarding the publication of this paper.

\section{References}

[1] International Energy Agency (IEA) (2021) Global EV Outlook 2021-Overview. International Energy Agency, Paris. https://www.iea.org/reports/global-ev-outlook-2021?mode=overview

[2] Bloomberg NEF (2021) Electric Vehicle Outlook 2021. https://about.bnef.com/electric-vehicle-outlook/

[3] McCormick, M. and Bushey, C. (2021) Biden Sets Electric Vehicle Target in Drive to Cut Emissions. Financial Times. https://www.ft.com/content/7fbc2d70-5365-4d3b-97ec-cea2756de28d

[4] Broom, D. (2021, January 20) 2020 Was a Breakthrough Year for Electric Vehicles. Here's Why. World Economic Forum. https://www.weforum.org/agenda/2021/01/electric-vehicles-breakthrough-tesla-chi na/ 
[5] Lane, B. (2016) Electric Vehicle Market Statistics. http://www.mjbradley.com

[6] Geotab, Inc. (2021, January 6) Addressing the Barriers to EV Adoption. http://www.geotab.com/energy

[7] Franke, T., Neumann, I., Bühler, F., Cocron, P. and Krems, J.F. (2012) Experiencing Range in an Electric Vehicle: Understanding Psychological Barriers. Applied Psychology, 61, 368-391. https://doi.org/10.1111/j.1464-0597.2011.00474.x

[8] Hardman, S. and Tal, G. (2021) Understanding Discontinuance among California's Electric Vehicle Owners. Nature Energy, 6, 538-545.

https://doi.org/10.1038/s41560-021-00814-9

[9] Lee, J.H., Chakraborty, D., Hardman, S.J. and Tal, G. (2020) Exploring Electric Vehicle Charging Patterns: Mixed Usage of Charging Infrastructure. Transportation Research Part D: Transport and Environment, 79, Article ID: 102249. https://doi.org/10.1016/j.trd.2020.102249

[10] Bingham, C., Walsh, C. and Carroll, S. (2012) Impact of Driving Characteristics on Electric Vehicle Energy Consumption and Range. IET Intelligent Transport Systems, 6, 29-35. https://doi.org/10.1049/iet-its.2010.0137

[11] Kambly, K. and Bradley, T.H. (2015) Geographical and Temporal Differences in Electric Vehicle Range Due to Cabin Conditioning Energy Consumption. Journal of Power Sources, 275, 468-475. https://doi.org/10.1016/j.jpowsour.2014.10.142

[12] Yao, E., Yang, Z., Song, Y. and Zuo, T. (2013) Comparison of Electric Vehicle's Energy Consumption Factors for Different Road Types. Discrete Dynamics in Nature and Society, 2013, Article ID: 328757. https://doi.org/10.1155/2013/328757

[13] Wager, G., Whale, J. and Braunl, T. (2016) Driving Electric Vehicles at Highway Speeds: The Effect of Higher Driving Speeds on Energy Consumption and Driving Range for Electric Vehicles in Australia. Renewable and Sustainable Energy Reviews, 63, 158-165. https://doi.org/10.1016/j.rser.2016.05.060

[14] Yuan, X., Li, L., Gou, H. and Dong, T. (2015) Energy and Environmental Impact of Battery Electric Vehicle Range in China. Applied Energy, 157, 75-84. https://doi.org/10.1016/j.apenergy.2015.08.001

[15] Yang, H., Gao, Y., Farley, K.B., Jerue, M., Perry, J. and Tse, Z. (2015) EV Usage and City Planning of Charging Station Installations. 2015 IEEE Wireless Power Transfer Conference, Boulder, 13-15 May 2015, 1-4. https://doi.org/10.1109/WPT.2015.7139139

[16] Li, C., Dong, Z., Chen, G., Zhou, B., Zhang, J. and Yu, X. (2021) Data-Driven Planning of Electric Vehicle Charging Infrastructure: A Case Study of Sydney, Australia. IEEE Transactions on Smart Grid, 12, 3289-3304. https://doi.org/10.1109/TSG.2021.3054763

[17] Bräunl, T., Harries, D., McHenry, M. and Wager, G. (2020) Determining the Optimal Electric Vehicle DC-Charging Infrastructure for Western Australia. Transportation Research Part D: Transport and Environment, 84, Article ID: 102250. https://doi.org/10.1016/j.trd.2020.102250

[18] Kavianipour, M., Fakhrmoosavi, F., Singh, H., Ghamami, M., Zockaie, A., Ouyang, Y., et al. (2021) Electric Vehicle Fast Charging Infrastructure Planning in Urban Networks Considering Daily Travel and Charging Behavior. Transportation Research Part D: Transport and Environment, 93, Article ID: 102769. https://doi.org/10.1016/j.trd.2021.102769

[19] Maia, R., Silva, M., Araujo, R. and Nunes, U. (2011) Electric Vehicle Simulator for Energy Consumption Studies in Electric Mobility Systems. 2011 IEEE Forum on 
Integrated and Sustainable Transportation Systems, Vienna, 29 June-1 July 2011, 227-232. https://doi.org/10.1109/FISTS.2011.5973655

[20] Dashora, Y., Barnes, J.W., Pillai, R.S., Combs, T.E., Hilliard, M. and Chinthavali, M.S. (2010) The PHEV Charging Infrastructure Planning (PCIP) Problem. International Journal of Emerging Electric Power Systems, 11, Article No. 7. https://doi.org/10.2202/1553-779X.2482

[21] Morrissey, P., Weldon, P. and O’Mahony, M. (2016) Future Standard and Fast Charging Infrastructure Planning: An Analysis of Electric Vehicle Charging Behavior. Energy Policy, 89, 257-270. https://doi.org/10.1016/j.enpol.2015.12.001

[22] Hunter, M., Mathew, J., Cox, E., Blackwell, M. and Bullock, D. (2021) Estimation of Connected Vehicle Penetration Rate on Indiana Roadways. JTRP Affiliated Reports, Paper No. 37. https://doi.org/10.5703/1288284317343

[23] Specifications, W.A.P.I. (2012) Vehicle API. https://vpic.nhtsa.dot.gov/api/

[24] INDOT (2021) INDOT: Wireless Electric Vehicle Charging Solution for Highway Infrastructure.

https://www.in.gov/indot/current-programs/innovative-programs/wireless-electricvehicle-charging-solution-for-highway-infrastructure/

[25] National Renewable Energy Laboratory (n.d.) All Stations API. https://developer.nrel.gov/docs/transportation/alt-fuel-stations-v1/all/

[26] Moloughney, T. (2021, February 12) EV Range Tests: Real-World Vs EPA. https://insideevs.com/reviews/443791/ev-range-test-results/ 